\title{
Article
}

\author{
Doi 10.5943/sif/ 2/1/9 \\ Copyright $\odot$ Mushroom Research Foundation
}

\section{Protostropharia luteonitens (Basidiomycota, Agaricales): new to China}

\section{Ma T$T^{1}$ and Ling $\mathrm{XF}^{\mathbf{1}}$}

${ }^{I}$ Research Institute of Resource Insects, Chinese Academy of Forestry, the Key Laboratory of Cultivating and Utilization of Resource Insects of State Forestry Administration, Kunming 650233, Yunnan, China

Ma T, Ling XF 2017 - Protostropharia luteonitens (Basidiomycota, Agaricales): new to China. Studies in Fungi 2(1), 71-75, Doi 10.5943/sif/2/1/9

\begin{abstract}
Protostropharia luteonitens is characterized by its pointedly papillate pileus, the large dark basidiospores, 2- spored basidia and absence of chrysocystidia. It is known from North America, Europe and Asia (Japan). In this paper, P. luteonitens is reported for the first time from China. This species is presented here with a full description, colour photographs, and line drawings.
\end{abstract}

Key words - Morphological characteristics - Strophariaceae - taxonomy

\section{Introduction}

The genus Protostropharia Redhead, Moncalvo \& Vilgalys 2013 had been treated as Subgenus Stercophila (Romagn. ex Noordel.) Noordel. 2011 or Sect. Stercophila (Romagn.) Sing. 1936 subordinated to genus Stropharia (Fr.) Quél 1872. Redhead et al. (2013) separated the genus Protostropharia from Stropharia by the formation of astrocystidia rather than acanthocytes on mycelium including that at the bases of basidiomes and in cracks and pockets within the dung substrate, as well as based on phylogenetic study of Moncalvo et al. (2002) and Walther et al. (2005).

Index fungorum (2017) documented nine species namely Protostropharia alcis (Kytöv.) Redhead 2013, P. arctica (Kytöv.) Redhead 2014, P. dorsipora (Esteve-Rav. \& Barassa) Redhead 2014, P. islandica (Kytöv.) Redhead 2014, P. luteonitens (Fr.) Redhead 2014, P. ochraceoviridis (García Mon.) C. Hahn 2014, P. ovalispora Y.W. Wang \& S.S. Tzean 2015, P. semiglobata (Batsch) Redhead, Moncalvo \& Vilgalys 2013 and P. tuberosa (H.C. Beardslee) Redhead 2014 with $P$. semiglobata as the type.

Protostropharia semiglobata, $P$. dorsipora and $P$. ovalispora have been reported from China (Bao 2014, Wang \& Tzean 2015) and among them, P. ovalispora was originally described from China. In this paper, we report P. luteonitens for the first time from China based on macro- and micro-morphological characteristics.

\section{Materials \& Methods}

Macro-morphological features were described based on fresh materials and documented by photographs. Fungal material was dried using an electric drier and deposited in the herbarium of the International Fungal Research and Development Centre (IFRDC), Research Institute of Resource Insects, Chinese Academy of Forestry. Color designations (e.g. 4A5; Buff-Yellow) were from Kornerup \& Wanscher (1981). Microscopic features were described from dried material mounted in $5 \% \mathrm{KOH}$, Congo red, or water, measured and illustrated under a compound microscope (Nikon 80i or E800). Terminology and methodology for descriptions see Ma et al. (2014). 


\section{Results}

\section{Taxonomy}

Protostropharia luteonitens (Fr.) Redhead, Index Fungorum 148: 1 (2014)

Figs. 1-2

Facesoffungi number: FoF 03260

Pileus 10-25 mm diameter, conic and brownish yellow (4B4, oac716) when young, then subconic to hemispheric and beige or straw yellow (3A3; oac814), pointedly papillate in centre, often slightly sulcate or striate at margin, shiny when dry, surface smooth, context whitish (1A1, oac909) and relatively hardish. Lamellae adnate, about $4 \mathrm{~mm}$ high, close or subdistant, pale gray (1B1, oac907) when young, then becoming yellowish brown (4B5, oac791) with purple tinge, edges serrulate and remaining whitish. Stipe $25-40 \mathrm{~mm} \times 1.0-3.0 \mathrm{~mm}$, cylindrical, nearly concoloured with that of pileus, stuffed to hollow, fragile; surface covered with white floccose scales; base of stipe with white mycelium, sometimes shaped pseudosclerotium; often with annuliform zone in upper half; context yellowish (1A2, oac900) to brownish (4B4, oac797), whitish (1A1, oac909) towards the surface. Odor mild.

Pileipellis an ixocutis, 15-200 $\mu \mathrm{m}$ thick, hyaline, made up of creeping, interwoven, colourless to dark yellowish, 1-5 $\mu \mathrm{m}$ wide filamentous hyphae; subpileipellis yellowish brown in $\mathrm{KOH}$, composed of interwoven, tubular to inflated tubular, 4-16 $\mu \mathrm{m}$ wide hyphae, the wall of hyphe sometimes incrusted with some blackish material. Stipitipellis also an ixocutis, 15-100 $\mu \mathrm{m}$ thick, composed of interwoven, hyaline, colourless to dark yellowish, 2-5 $\mu \mathrm{m}$ filamentous wide hyphae, the wall of hyphe smooth or rough. Subhymenium subcellular, composed of irregular vesicular cells. Hymenophoral trama subregular to interwoven, with cylindrical hyphae 2-13 $\mu \mathrm{m}$ diam, hyaline, colourless to dark yellowish, wall smooth or sometimes slightly rough. Basidia 28$37.5 \times(9-) 10.5-15.5 \mu \mathrm{m}$, hyaline and colourless, subcylindric to clavate, 2-spored and 1-spored, rarely 3-spored, sterigmata $(2-) 3-7(-8) \mu \mathrm{m}$. Basidiospores $(108 / 3 / 1)(13.5-) 14.5-20(-25) \times(8-) 9-$ $12.5(-16) \times(7.5-) 8.5-12.5 \mu \mathrm{m}$, ellipsoid or subellipsoid in face view, $\mathrm{Q}=(1.4-) 1.5-1.7(-1.8), \mathbf{Q}=$ $1.59 \pm 0.08$; ellipsoid or subellipsoid in side view, $Q=(1.3-) 1.5-1.8(-1.9), \mathbf{Q}=1.65 \pm 0.10$, purplish brown in water, yellowish brown in $\mathrm{KOH}$, dark purplish brown in deposit; wall smooth, thick (1$1.5 \mu \mathrm{m})$ and complex, with distinct $1.5-3 \mu \mathrm{m}$ wide, often slightly eccentric in side view apical germ pore. Cheilocystidia 20-35 × (4-)5-9(-11) $\mu \mathrm{m}$, hyaline and colourless, occasionally yellowbrownish, cylindric, cylindric-clavate, clavate to sublageniform, often with a rounded apex. Caulocystidia abundant, $18-63 \times 3.5-8(-10.5) \mu \mathrm{m}$, hyaline, colourless to yellow-brownish, cylindric, sometimes clavate or sublageniform, often more or less flexuous. Clamp connections abundant.

Known distribution - Known from North America, Europe and Asia (Japan) (Guzmán 1983, Stamets 1996, Noordeloos 2011), found for the first time in Yunnan Province, southwest China.

Habitat - Growing scattered to gregarious on soil of a meadow close to a river where cattles and horses have grazed in summer.

Material examined - CHINA, Yunnan Province: Zhaotong, Zhaoyang district, Tiaodun river of Dashanbao, 27²4'37.6"N, 103¹7'34.5"E, elevation 3132 m, 30 Aug 2011, Tao Ma and XiaoFei Ling, ZY029 (IFRD415163).

\section{Discussion}

Protostropharia luteonitens is characterized by its pointedly umbonate pileus, glutinous pileus and stipe, the annulus or annular zone on stipe, sometimes with a pseudosclerotium of the stipe (Clémençon \& Roffler 2003), as well as large dark basidiospores, 2-spored basidia and absence of chrysocystidia. Protostropharia luteonitens is morphologically similar to P. semiglobata and $P$. dorsipora because of the morphologically similar basidiocarps, but $P$. luteonitens can be easily separated from $P$. semiglobata and $P$. dorsipora by the pointedly umbonate pileus, 2 -spored basidia and absence of chrysocystidia. Among the species of the genus Protostropharia, 
P. islandica also doesn't have chrysocystidia, but it has stout basidiocarps, 4-spored basidia and smaller basidiospores (Kytövuori 1999, Noordeloos 2011).

Protostropharia luteonitens mostly has 2-spored basidia only, sometimes it also has 4-spored basidia (Kytövuori 1999), while Guzmán (1983) recorded P. luteonitens with 4-spored, or 1-2spored basidia. Specimens of $P$. luteonitens from Yunnan, southwest China has 2- and 1- spored larger basidia than previously recorded specimens from other regions of the world (Kytövuori 1999, Guzmán 1983).
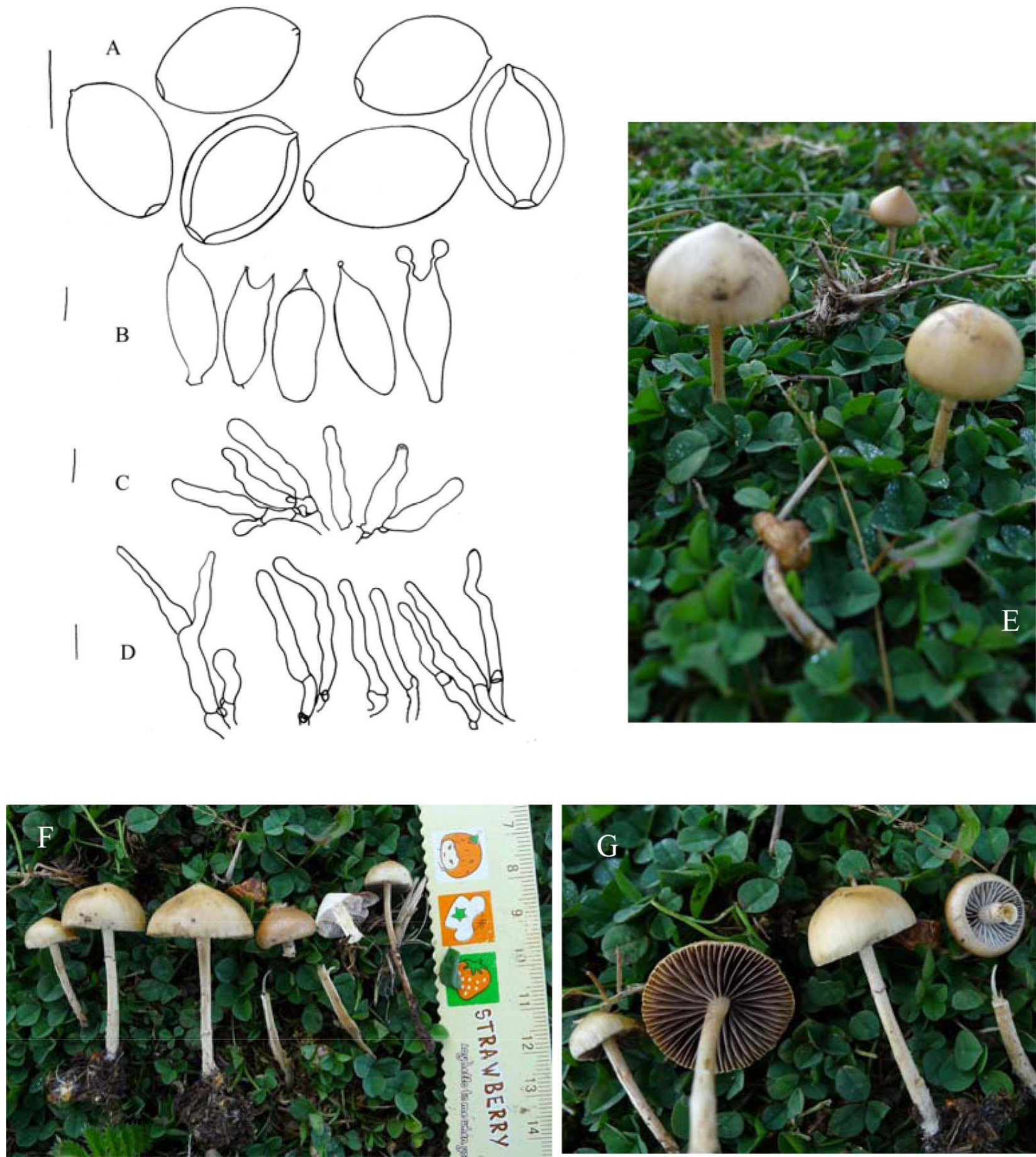

Fig. 1 - Protostropharia luteonitens A Basidiospores. B Basidia. C Cheilocystidia. D Caulocystidia. E-G Basidiocarps in the field. Scale bars: $A-D=10 \mu \mathrm{m}$. 

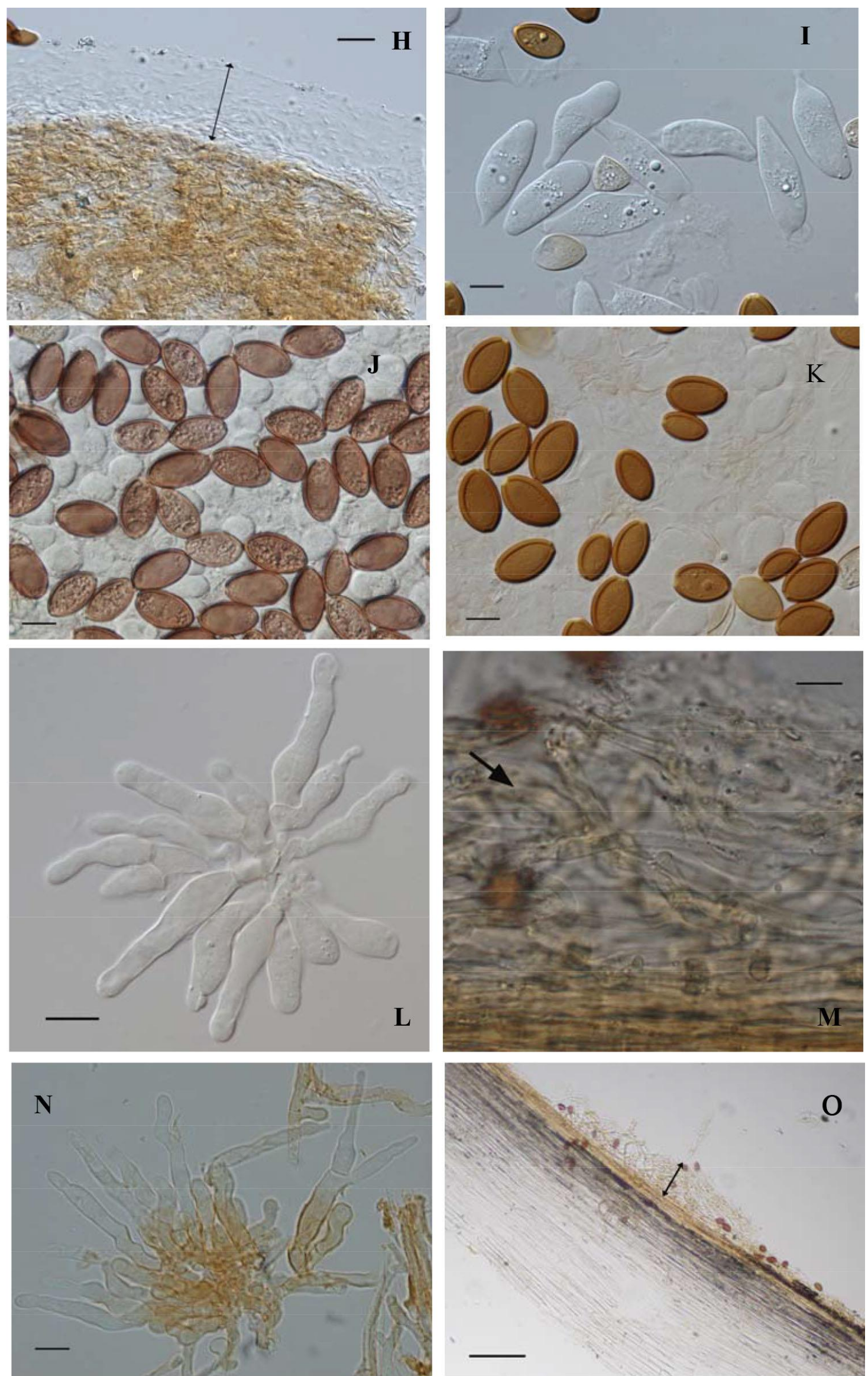

Fig. 2 - Protostropharia luteonitens H Pileipellis 400x. I Basidia 1000x. J Basidiospores mounted in water, 1000×. K Basidiospores in KOH, 1000×. L Cheilocystidia 1000×. M Stipitipellis 1000×. N Caulocystidia 1000x. O Stipitipellis 100x. Scale bars: $\mathrm{I}-\mathrm{N}=10 \mu \mathrm{m} . \mathrm{H}=20 \mu \mathrm{m} . \mathrm{O}=100 \mu \mathrm{m}$. 
Protostropharia luteonitens is widely distributed throughout the Northern temperate zones, but it seems to be rare or very rare in its range (Guzmán 1983, Kytövuori 1999, Noordeloos 2011). This is the first report of $P$. luteonitens from China, which seems to be very rare in Yunnan Province, in four years of collection throughout Yunnan Province, we only found one specimen of P. luteonitens at $3132 \mathrm{~m}$ altitude.

\section{Acknowledgements}

This work was financed by the Grant for Essential Scientific Research of Chinese National Nonprofit Institute (no. riricaf2011003z and Riri200707M).

\section{References}

Bau T. 2014 - Strophariaceae (1). Flora Fungorum Sinicorum vol.49. Science Press, Beijing.

Clémençon H, Roffler U. 2003 - The pseudosclerotia of the agaric Stropharia luteonitens. Mycological Progress 2(3), 235-238.

Guzmán G. 1983 - The genus Psilocybe. Beih. Nova Hedwigia 74, Cramer, Vaduz.

Hahn C. 2014 - Ein bayerischer Nachweis von Protostropharia dorsipora mit Anmerkungen zur Gattung Protostropharia und kommentiertem Bestimmungsschlüssel. Mycologia Bavarica. $15,19-32$.

Index Fungorum. 2017 - http://www.indexfungorum.org/Names/Names.asp (accessed on March 21, 2017).

Kornerup A, Wanscher JH. 1981 - Taschenlexikon der Farben (3. Aufl.). Muster-Schmidt Verlag, Göttingen.

Kytövuori I. 1999 - The Stropharia semiglobata group in NW Europe. Karstenia 39(1), 11-32.

Moncalvo JM, Vilgalys R, Redhead SA, Johnson JE, James TY, Aime MC, Hofstetter V, Verduin SJW, Larsson E, Baroni TJ, Thorn RG, Jacobsson S, Clémençon H, Miller Jr OK. 2002 One hundred and seventeen clades of euagarics. Molecular Phylogenetics and Evolution 23(3), 357-400.

Ma T, Feng Y, Lin XF, Karunarathna SC, Ding WF, Hyde KD. (2014) Psilocybe chuxiongensis, a new bluing species from subtropical China. Phytotaxa 156 (4), 211-220.

Noordeloos ME. 2011 - Strophariaceae s.l. Fungi Europaei Vol. 13. Edizioni Candusso, Alassio, Italy.

Redhead SA. 2013 - Nomenclatural novelties. Index Fungorum 15, 1-2.

Redhead SA. 2013 - Nomenclatural novelties. Index Fungorum 18, 1.

Redhead SA. 2014 - Nomenclatural novelties. Index Fungorum 148, 1.

Redhead SA. 2014 - Nomenclatural novelties. Index Fungorum 158, 1.

Stamets P. 1996 - Psilocybin mushrooms of the world. Ten Speed Press, Berkeley, USA.

Walther G, Garnica S, Weiß M. 2005 - The systematic relevance of conidiogenesis modes in the gilled Agaricales. Mycological Research 109(5), 525-544.

Wang YW, Tzean SS. 2015 - Dung-associated, potentially hallucinogenic mushrooms from Taiwan. Taiwania 60(4), 160-168. 